\title{
O Papel do Instagram na Decisão de Compras de Viagens de Lua de Mel: Um Estudo Sob a Perspectiva das Noivas
}

\author{
Instagram's Role in the Honeymoon Travel Purchasing Decision: A Study \\ from a Bride's Perspective
}

\author{
Lia Chagas de Lima \\ Universidade Estadual do Ceará | Av. Dr. Silas Munguba, 1700, 60714903 Fortaleza | Brasil | \\ https://orcid.org/0000-0001-7481-964X | liac.delima@gmail.com
}

Dra. Nathália de Sousa Pereira

Universidade Estadual do Ceará | Av. Dr. Silas Munguba, 1700, 60714903 Fortaleza | Brasil |

https: //orcid.org/0000-0002-3831-123X | nathaliaeng.producao@gmail.com

\section{Danielle Miranda de Oliveira Arruda Gomes}

Universidade Estadual do Ceará | Av. Dr. Silas Munguba, 1700, 60714903 Fortaleza | Brasil |

https://orcid.org/0000-0002-6209-6349| daniellearrudagomes@gmail.com

Fechas | Recepción: 15/04/2021 | Aceptación: 06/06/2021

\section{Resumo}

É cada vez mais perceptível, o poder de influência que as redes sociais têm sobre o comportamento do consumidor. Nesse sentido, este estudo buscou compreender como as postagens no Instagram influenciam no processo de decisão de compra de destinos turísticos de lua de mel. Além disso, foram delineados os seguintes objetivos específicos: identificar os tipos de postagens realizadas sobre turismo no Instagram que chamam atenção das noivas; identificar os principais influenciadores do processo de decisão de compra de destinos turísticos de lua de mel; e propor um framework do processo de decisão de compra de destinos turísticos de lua de mel. Assim, foi realizada uma pesquisa qualitativa exploratória, conduzida por entrevistas de profundidade. Foram encontrados dois tipos de postagens que mais chamam atenção das noivas: enfoque na estética e enfoque na estrutura turística. Identificaram-se ainda quatro tipos principais de influenciadores de

\begin{abstract}
It is increasingly noticeable, the power of influence that social networks have on consumer behavior. In this sense, this study sought to understand how posts on Instagram influence the decision to purchase honeymoon tourist destinations. Also, the following specific objectives were outlined: to identify the types of tourism posts on Instagram that attract the attention of brides; identify the main influencers in the decision-making process for the purchase of tourist honeymoon destinations and propose a framework for the decisionmaking process for the purchase of honeymoon tourist destinations. Thus, exploratory qualitative research was conducted, conducted by in-depth interviews. Two types of posts were found that must attract the attention of brides: Focus on aesthetics and focus on the tourist structure. Four main types of influencers of honeymoon tourist destinations on Instagram were also identified. It became evident that travel posts on Instagram play a relevant role in
\end{abstract}


destinos turísticos de lua de mel presentes no Instagram. Evidenciou-se que as postagens sobre viagens no Instagram atuam de forma relevante na decisão de compra de um destino turístico de lua de mel, pois os usuários que postam atuam como cocriadores das estratégias mercadológicas de conteúdo, mesmo sem ter intenção desta influência. Por fim, foi desenvolvido um framework do processo de decisão de compra de um destino turístico de lua de mel que mostrou que o Instagram é uma ferramenta essencial, pois o processo de decisão de compra se inicia nele antes da viagem e no final é retornado a ele através das postagens após ou durante as viagens.

Palabras clave: instagram, decisão de compra, destino turístico, lua de mel. the decision to purchase a honeymoon tourist destination, as the users who post act as cocreators of content marketing strategies even without having the intention of this influence. Finally, a framework for the purchase decision process for a honeymoon tourist destination was developed, which showed that Instagram is an essential tool, as the purchase decision process starts there before the trip and at the end is returned to him through posts after or during travel.

Keywords: instagram, purchase decision, tourist destination, honeymoon.

\section{INTRODUÇÃO}

A evolução da internet trouxe avanços tanto aos consumidores quanto às organizações no sentido de proporcionar novas formas de comunicação e acesso às informações em geral (Xiang, Du, Ma \& Fan, 2017; Prentice, Han, Hua \& Hu et al., 2019). Com o advento das redes sociais, os usuários começaram a exercer papéis mais ativos e a valorizar os novos modos de interação social (Jablonska, 2017; Tavakoli \& Mura, 2018). Assim, as opiniões dos internautas passaram a ser tão, ou mais, significativas e influentes quanto as informações institucionais publicadas nas redes sociais e conquistaram espaço no processo de decisão de compra dos consumidores (Brandt, Bendler \& Neumann, 2017).

As redes sociais proporcionam uma rede de conhecimento coletivo através do compartilhamento no ambiente online (Tavakoli \& Mura, 2018). Um exemplo disto pode ser observado através dos compartilhamentos de imagens do cotidiano que podem ser vistas a qualquer momento por seus seguidores. Logo, as redes sociais podem funcionar como um álbum da vida de seus usuários (Sholeh \& Rusdi, 2019).

Dentre as redes sociais existentes, uma em especial vem ganhando notoriedade, principalmente pelo público mais jovem, o Instagram (Dantas \& Abreu, 2020). De acordo com o estudo realizado por Varma, Dhakane e Pawar (2020), 68\% dos usuários de rede social passam a maior parte do tempo no Instagram e dentre os conteúdos mais compartilhados estão as imagens de locais visitados e monumentos históricos (Mukhina, Rakitin \& Visheratin, 2017). Trata-se de uma rede social essencialmente visual, que oferece a oportunidade dos seus usuários se comportarem como agentes promotores de um destino turístico, influenciando no processo de decisão de compra (Yilmaz, 2017; Anagnostopoulou, Buhalis, Kountouri, Manousakis \& Tsekrekos, 2019). Dessa forma, pode-se dizer que o Instagram assumiu um papel importante na propagação, fortalecimento e divulgação de uma destinação turística.

De acordo com a pesquisa de Pourfakhimi, Duncan e Coetzee (2020), existe uma necessidade de estudos nas áreas do comportamento do consumidor no setor do turismo referente à 
utilização das redes sociais pelos usuários para a tomada de decisões. A maioria das pesquisas sobre compartilhamento de experiências tem como enfoque a comunicação verbal ou escrita (Mukhina et al., 2017; Shuqair \& Cragg, 2017; Barasch, Zauberman \& Diehl, 2018), mas o compartilhamento de experiências por meio de fotos carece de investigações mais aprofundadas para uma melhor compreensão.

Diante dessas evidências, percebe-se que o Instagram está cada vez mais presente no cotidiano das pessoas e o compartilhamento de imagens por meio dessa rede social pode exercer uma influência relevante na decisão de compra dos consumidores. Dessa forma, a pesquisa evidenciou uma lacuna teórica relevante ao não encontrar na literatura estudos que mostrassem essa influência no processo decisório de compra de destinos turísticos de lua de mel.

A seleção do destino de lua de mel é realizada em conjunto, pelo casal, ou por um dos futuros cônjuges (Jang, Lee, Lee \& Hong, 2007; Ünal, Dursun \& Caber, 2017). Neste estudo, buscou-se compreender este fenômeno pela perspectiva das noivas, a fim de responder ao problema de pesquisa proposto. Este trabalho faz parte de um projeto mais amplo, que envolve duas outras fases além desta: análise sob a perceptiva dos noivos e compreensão da dinâmica da decisão em casal.

Assim, o estudo gira em torno da problemática: Como as postagens no Instagram influenciam no processo de decisão de compra de destinos turísticos de lua de mel? O objetivo geral do estudo consistiu em compreender como as postagens no Instagram influenciam no processo de decisão de compra de destinos turísticos de lua de mel. Os objetivos específicos foram assim delineados: i) identificar os tipos de postagens realizadas sobre turismo no Instagram que chamam atenção das noivas; ii) identificar os principais influenciadores do processo de decisão de compra de destinos turísticos de lua de mel; e iii) propor um framework do processo de decisão de compra de destinos turísticos de lua de mel.

Com este estudo, pretende-se contribuir com a academia ao aprofundar o conhecimento sobre a influência das imagens publicadas no Instagram no processo de decisão de compra de um destino turístico de lua de mel e, assim, entender como as imagens compartilhadas pelos usuários do Instagram contribuem para a construção da imagem do destino turístico e para sua promoção.

\section{PROCESSO DE DECISÃO DE COMPRA ONLINE}

Os estudos sobre a tomada de decisão do consumidor e o processo de decisão de compra são amplos. Autores clássicos apresentam em seus estudos o processo decisório de compra constituído por cinco fases: reconhecimento da necessidade, busca de informação, avaliação das alternativas, compra e avaliação pós-compra (Sheth, Mittal \& Newman, 2001; Mowen \& Minor, 2006; Schiffman \& Kanuk, 2009). Já outros autores retratam o modelo PDC- Processo de Decisão do Consumidor constituído de sete fases, onde separam a fase de compra da fase de consumo e ainda adicionam a fase de descarte (Blackwell, Miniard \& Engel, 2008; Solomon, 2011).

Ao observar os processos de decisão de compra tradicionais, notou-se que estes foram desenvolvidos com os atributos do ambiente offline, fazendo-se necessário ampliá-los incluindo, nesse processo, novos elementos e atributos do ambiente digital. Se antes as 
interações humanas eram feitas face a face, hoje, com a popularização das mídias sociais, essa conjuntura foi alterada (Handel \& Schwartzstein, 2018). A web 2.0 permitiu o encontro do online com o offline, atribuindo poder às pessoas, pois elas agora não só consomem, como também produzem conteúdo, influenciando assim na tomada de decisão (Fernández \& García, 2020).

Nesse sentido, Lecinsk (2011) desenvolveu o primeiro modelo de processo de decisão de compra incluindo o ambiente digital (Figura 1). De acordo com o autor, no modelo clássico, o consumidor recebia o estímulo e a decisão de compra era tomada na hora da aquisição, após conversar com o vendedor ou prestador de serviço. Com a difusão das informações, por meio da web 2.0, o consumidor passou a ter acesso rápido e de forma fácil ao produto ou serviço que deseja consumir, passando então a tomar a decisão da compra antes de entrar na loja.

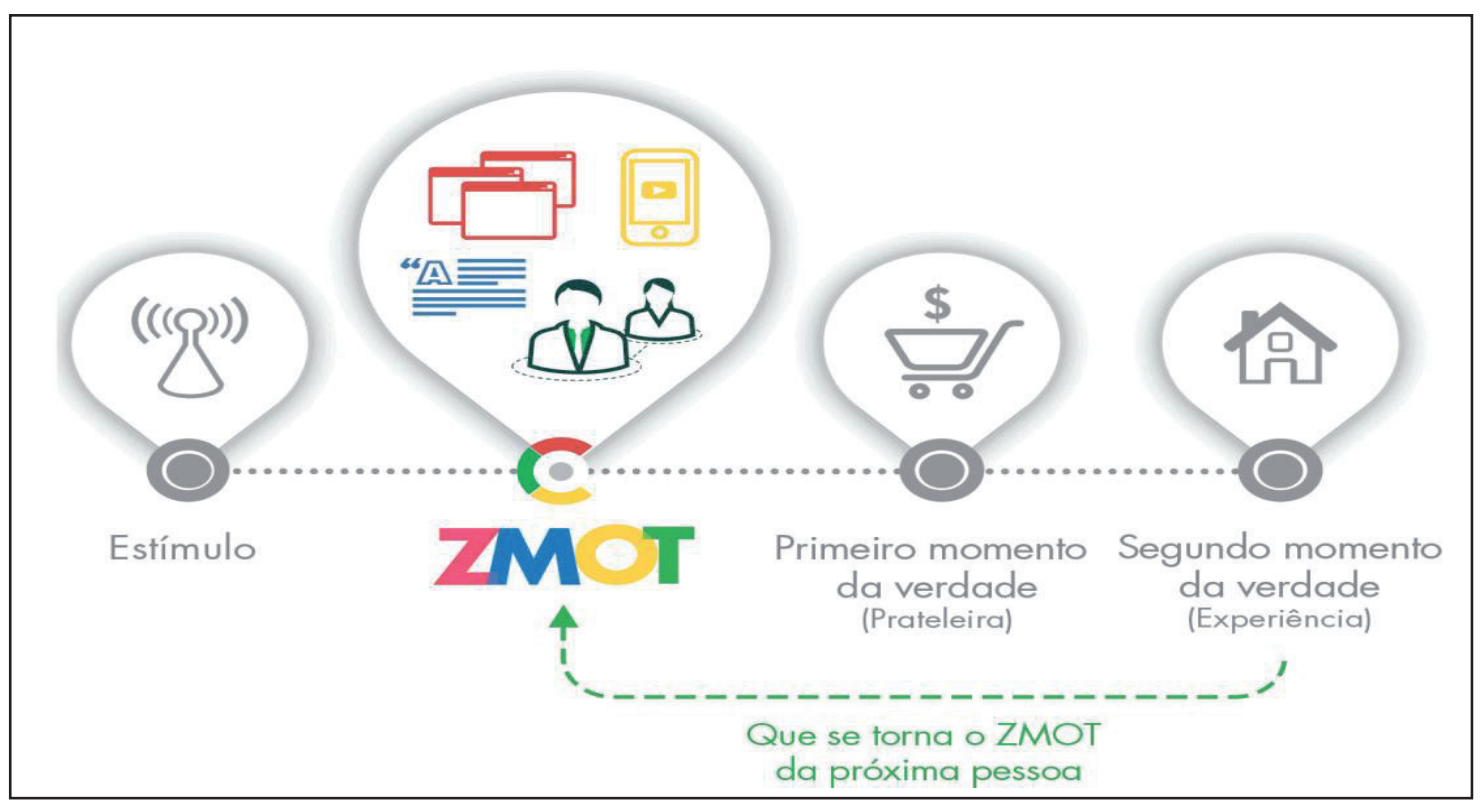

Figura 1 - Novo modelo mental de tomada de decisão do consumidor

Fuente: Lecinsk (2011, p. 17).

O modelo apresentado é chamado de ZMOT (Zero Moment of Truth), em português, momento zero da verdade, e tem como característica principal o fato de o consumidor buscar informações online para auxiliar a tomada de decisão (Lecinski, 2011). Assim, o consumidor, ao receber um estímulo, busca, na internet, informações de pessoas que já fizeram uso do produto ou serviço, e a decisão final da compra acontece nesse momento zero da verdade (Arora, Bansal, Kandpal, Aswani \& Dwivedi, 2019; Prentice et al., 2019). A Figura 2 apresenta outras características do ZMOT. 


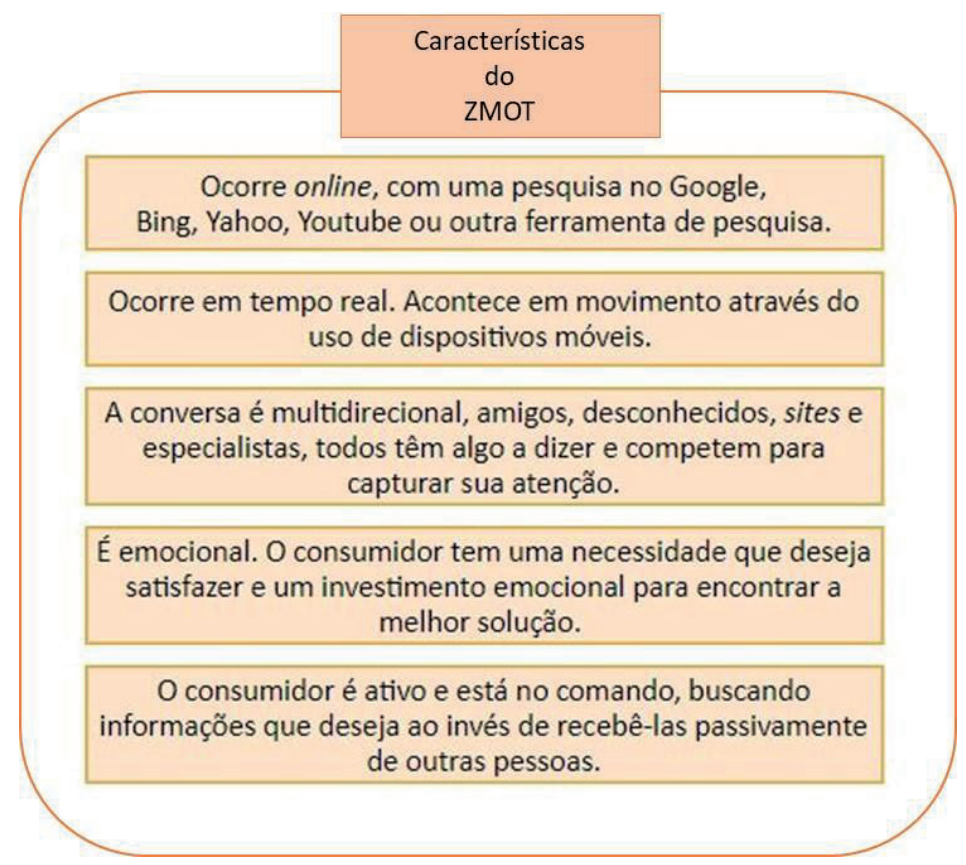

Figura 02 - Características do ZMOT

Fuente: adaptada de Lecinsk (2011).

Ao realizar a compra, o consumidor passa para o segundo momento da verdade, experiência, onde ele compartilha na internet informações do produto ou serviço que irá se tornar o ZMOT de outro consumidor. Essa forma de electronic Word-Of-Mouth (eWOM) têm influenciado significativamente a intenção, comportamento e decisão de compra dos consumidores (Sharifi, 2018; Sharma \& Aggarwal, 2019). O eWOM se tornou uma fonte confiável de informação para turistas, pois eles veem as informações compartilhadas em rede como não comerciais, autênticas, experienciais e detalham o produto turístico (Ait-bakrim, Attouch, Guerreiro \& Perez-Aranda, 2019).

Antes de viajar, o turista realiza pesquisas em sites, blogues e portais na internet. Consulta as redes sociais e pede dicas. Faz comparação de preços de hotéis, passagens aéreas e outros serviços (Silva, Silvia, Marques Junior \& Mendes Filho, 2020; Xu, 2020). Durante a viagem, continua realizando pesquisas sobre o que ver, o que comer ou visitar, tira várias fotos e vídeos do destino e publica o seu conteúdo em tempo real nas redes sociais (Tan, LV, Liu \& Gursoy, 2018; Lima \& Arruda, 2019). Nessas publicações, recomenda-se lugares e restaurantes, e, depois da viagem, o turista relata sua experiência, publica nas redes sociais, contando o melhor e o pior da sua viagem, realiza avaliações, sugere ou não empresas e produtos (ReyesMenendez, Correia, Matos \& Adap, 2020).

Assim, percebe-se que no setor do turismo as informações compartilhadas por outros viajantes têm sido extremamente úteis para o planejamento de viagens, visto que os futuros viajantes certamente as utilizarão para buscar informações sobre produtos e serviços turísticos que pretendem comprar (Hlee, Lee, \& Koo, 2018; Litvin, Goldsmith \& Pan, 2018; Sharifi, 2018). Após a compra o turista compartilha sua experiência na rede, que servirá como fonte de informação para outros consumidores.

\subsection{Instagram como fonte de informações de destinos turísticos}


É cada vez mais perceptível, o poder de influência que as redes sociais online têm sobre as interações sociais e, consequentemente, sobre o comportamento do consumidor (Barasch, et al., 2018). A web 2.0 ampliou, por meio da expansão do ambiente online, as trocas de ideias, experiências e sentimentos que fazem do ser humano um ser social (Fernández \& García, 2020).

Uma explicação para isso deve-se ao manuseio dos conteúdos gerados nas redes sociais que são acessíveis e fáceis de utilizar (Liu, Mehraliyev, Liu \& Schuckert, 2019). Assim, a distribuição das informações on-line tem alcançado grandes números (Arora, et al., 2019; Prentice et al., 2019).

O Instagram vem se destacando devido ao seu espaço propício às publicações por meio de postagens que qualquer tipo de usuário pode fazer em sua conta (Dantas \& Abreu, 2020). A funcionalidade central do Instagram está relacionada ao compartilhamento de fotos e de vídeo. Além disso, os usuários recebem um feedback, como comentários e curtidas de outros usuários (Sholeh \& Rusdi, 2019; Varma et al., 2020).

É devido às características desse meio de comunicação digital, que podem ser exploradas situações em contexto turístico, tais como promoção de destinos, monumentos e gastronomia, tudo numa perspectiva global, rápida e interativa. Essas redes sociais podem ser úteis neste setor, devido à sua capacidade para captar o interesse do consumidor e influenciar a sua decisão (Lima \& Arruda, 2019).

As formas de planejar uma viagem mudaram com a web 2.0 e as redes sociais, pois os viajantes buscam informações com mais segurança, valorizando a espontaneidade e a veracidade das postagens. É por isso que o processo de decisão sobre qual destino visitar é baseado, na maioria das vezes, nas recomendações de prescritores próximos, familiares e amigos, bem como nos comentários e avaliações de outros viajantes presentes no Instagram (Dantas \& Abreu, 2020; Fernández \& García, 2020).

Ao relacionar o compartilhamento de informações de destinos turísticos, estudos mostram que $46 \%$ das pessoas gostam de compartilhar conteúdos sobre viagens com suas famílias e amigos. Além disso, em relação ao planejamento turístico, $28 \%$ dos usuários no Instagram apreciam exibir seus planos de viajar (Varma et al., 2020).

Ao comparar os motivos de tirar fotos em pontos turísticos, Barasch et al. (2018) relataram em sua pesquisa que $35,3 \%$ das pessoas afirmaram que tiravam fotos com o objetivo de capturar memórias para si próprias (preservar memórias), enquanto 52,3 \% afirmaram que tiram fotos para compartilhar com outros em postagens no Instagram.

As fotografias têm se tornado ferramentas fundamentais para criação e promoção da imagem de destinos turísticos, apresentando características dos lugares, suas qualidades e atributos (Varkaris \& Neuhofer, 2017; Hlee et al., 2018). Nesse sentido, o desejo das pessoas de buscar informações sobre experiências já vivenciadas por outras, ajuda nas decisões de consumo (Guillet, Kucukusta \& Liu, 2016; Lui, Bartosiak, Piccoli, \& Sadhya, 2018). Dessa maneira, o ambiente online representa um lugar onde as pessoas conseguem obter informações, planejar viagens, escolher um destino e comparar a escolha com as sugestões de outros usuários (Lin, Bruning \& Swarna, 2018; Leung, Sun \& Bai, 2019). 
Percebe-se que o Instagram possibilita aos usuários uma gama de informações vindas de diferentes fontes. Desse modo, os consumidores necessitam de mais confiança e, assim, buscas por relatos e experiências pessoais são mais atraentes, intensificando a troca de informações no meio eletrônico (Gao, Li, Liu \& Fang, 2018).

\section{METODOLOGIA}

O presente estudo é de cunho qualitativo. Essa abordagem é indicada por Creswell (2014) quando o objetivo de explorar fatores envolve fenômenos, apresentando perspectivas ou significados atribuídos pelos indivíduos ou grupos a um problema social. Quanto aos objetivos, é exploratória, por se tratar de um campo ainda recente, tendo vertentes pouco exploradas. 0 caráter descritivo também tipifica esse estudo, pois se buscou evidenciar as características presentes em determinado campo e fenômeno (Vergara, 2016).

O critério de seleção da amostra consistiu na técnica "bola de neve" (Snowball Sample). Tratase de um tipo de amostra não probabilística, que utiliza cadeias de referência (Vergara, 2016). Neste processo de múltiplos estágios, a população é selecionada em um contexto social. Os primeiros elementos amostrais são convidados a introduzir outras pessoas a fazerem parte da pesquisa, em um processo contínuo, que se desenvolve em cadeia, até alcançar a saturação dos dados (Naderifar, Goli \& Ghaljaie, 2017). Snowball Sample é uma técnica útil para reunir informação em grupos específicos de pessoas (Naderifar et al., 2017), como é o caso das noivas.

Com relação ao tamanho da amostra, adotou-se o critério de saturação empírica, que ocorre quando os dados coletados são julgados suficientes pelo pesquisador (Fontanella \& Júnior, 2012). Dessa forma, após um certo número de entrevistas, observando uma repetição dos dados coletados, o pesquisador decide que novas informações recolhidas já não agregariam mais valor, encerrando o processo de coleta de dados (Pires, 2008).

A coleta de dados se deu por meio de entrevista não estruturada focalizada, com o intuito de obter informações singulares e interpretações sustentadas pelo entrevistado (Stake, 2011). Na primeira etapa ocorreu a exploração do campo de estudo e a elaboração dos roteiros. Foi realizado um pré teste com três entrevistas com o objetivo de aprimorar e validar o roteiro. $\mathrm{Na}$ segunda etapa, o instrumento de coleta de dados foi aplicado aos demais sujeitos. Assim, foram realizadas doze entrevistas, gravadas e posteriormente transcritas e analisadas, com noivas na faixa etária entre 25 e 35 anos.

A técnica utilizada para análise dos dados foi a Análise de Conteúdo proposta por Bardin (2011), que tem por intuito obter indicadores, por meio da descrição sistemática e objetiva do conteúdo das mensagens, fazendo inferências de conhecimentos relacionados e atribuindo significados que vão além das mensagens concretas.

Seguiu-se as seguintes etapas preconizadas por Bardin (2011): pré-análise, exploração do material e tratamento dos resultados. Durante a pré-análise, o material foi organizado para ser analisado com o objetivo de torná-lo operacional, através da sistematização das ideias iniciais. A segunda etapa, caracterizada pela exploração do material, consistiu na definição de categorias e na identificação das unidades de conteúdo e de contexto nos documentos. Por fim, foi realizado o tratamento dos resultados por meio da análise reflexiva e crítica das 
informações, que foram analisadas e interpretadas. Para a operacionalização do trabalho de análise, foi utilizado o software Atlas $\mathrm{Ti}^{\circledR}$.

\section{APRESENTAÇÃO DA ANÁLISE DOS RESULTADOS}

\subsection{Tipologia de postagens de turismo que mais chamam atenção no Instagram}

As postagens analisadas no Instagram se apresentam através de fotografias, vídeos ou textos, podendo estes textos serem isolados ou vinculados às fotografias e aos vídeos. Sobre a preferência dessas postagens, as noivas afirmaram que, por mais que as fotos sejam bonitas e despertem curiosidade, os vídeos são bem mais atraentes e remetem à emoção, pois conseguem trazer uma maior realidade do local.

De acordo com as respondentes, as postagens de viagem despertam a atenção quando mostram imagens que fogem do convencional do dia a dia. São fotografias e vídeos que trazem diferenciais como belezas naturais, monumentos históricos, dentre outros. Elas podem trazer dicas de restaurantes, locais para visitar, informações sobre os hotéis e descrições das experiências que se teve nesses locais.

Através da análise do conteúdo obtido, foi possível categorizar duas diferentes vertentes de postagens. O primeiro tipo foi intitulado de Postagens Estéticas, pois são relacionadas às características com apelo visual envolvendo a natureza, romantismo e gastronomia. Já o segundo tipo foi intitulado como Postagens com Enfoque na Estrutura Turística, nas quais se referem aos serviços hoteleiros, atrações turísticas, bares e restaurantes. O Quadro 1 detalha essas categorias juntamente com suas subcategorias e descrições.

Quadro 1- Tipologias de postagens de turismo que mais chamam atenção no Instagram

\begin{tabular}{|c|c|c|}
\hline Categorias & Subcategorias & Descrição \\
\hline Postagens Estéticas & $\begin{array}{c}\text { - Belezas Naturais } \\
\text { - Românticas } \\
\text { - Gastronomia }\end{array}$ & $\begin{array}{c}\text { Postagens de fotos e vídeos com apelo } \\
\text { visual: imagens de paisagens paradisíacas, } \\
\text { cenas românticas e comidas saborosas. }\end{array}$ \\
\hline $\begin{array}{c}\text { Postagens com Enfoque na } \\
\text { Estrutura Turística }\end{array}$ & $\begin{array}{c}\text { - Serviços hoteleiros } \\
\text { - Atrações turísticas }\end{array}$ & $\begin{array}{c}\text { Postagens com informações das estruturas } \\
\text { turísticas: serviços hoteleiros, atrações } \\
\text { turísticas, bares e restaurantes }\end{array}$ \\
\hline
\end{tabular}

Fuente: elaborado pelas autoras (2021).

Em relação aos tipos de postagens voltadas à estética, alguns entrevistados afirmaram que não conheciam o local escolhido, conheceram por meio de postagens no Instagram, gostaram e decidiram ir em sua lua de mel. Percebe-se que entre eles o que chama a atenção nas postagens é o forte apelo visual, que desperta o interesse de conhecer o lugar.

Quando vejo fotos no Instagram de lugares que eu não conheço, dou logo um print das imagens para guardar. Principalmente, quando são fotos bonitas e diferentes. (E9) 
Depois que fiquei noiva comecei a prestar mais atenção nas postagens de viagem das pessoas no Instagram, pois eu tinha que decidir um local de lua de mel. E foi assim, vendo fotos e vídeos da minha prima que escolhi ir para o mesmo lugar. (E7)

Ainda sobre postagens com apelo visual, algumas entrevistadas afirmaram que o romantismo das cenas nas fotografias aumentava o desejo de ir para o mesmo local e fazer a mesma pose na foto. Inclusive, algumas noivas mudaram a decisão do destino de suas viagens de lua de mel após terem visualizado algumas postagens no Instagram. Já outras entrevistadas afirmaram que inseriram outros locais para visitar além dos planejados, após verem postagens informando e sugerindo locais próximos aos destinos escolhidos que deveriam ser visitados também. Para elas, essas sugestões foram fundamentais para conhecer locais que até então não estavam previstos no planejamento da lua de mel.

Quanto ao segundo tipo intitulado como postagens voltadas à estrutura, os entrevistados afirmaram que além do apelo visual de fotos e vídeos, observaram informações mais técnicas como informações sobre serviços hoteleiros, atrações turísticas e recomendações de bares e restaurantes. Esses tipos de postagens servem como dicas e informações a mais que são colocadas na descrição da imagem ou do vídeo e assim, os usuários salvam essas referências para uma possível viagem.

Eu vi as fotos do hotel e dos passeios que ela fez, então na hora de decidir o hotel eu escolhi o mesmo e fiz os mesmos passeios que ela fez, pois eu confiava nas informações que ela tinha compartilhado (E5).

As fotos do hotel eram lindas. Na cidade, ela também mostrava vários restaurantes com comidas. Então eu decidi ir para o mesmo destino (E3).

Além disso, alguns entrevistados afirmaram que a atitude de se colocar as localizações específicas dos locais visitados, torna-se relevante para quem olha, pois ajuda na busca por informações mais detalhadas de onde fica o local e como se pode chegar. Também se percebeu, entre os entrevistados, um certo grau de seletividade, interesse por postagens de viagens diferentes, lugares incomuns e comida exótica.

Foi possível observar ainda que alguns tipos de postagens podem ter um caráter informativo. Conforme os resultados, essas informações instigam as noivas a conhecerem os lugares evidenciados nas postagens durante a lua de mel e esclarecem detalhes e dúvidas sobre a paisagem postada, por exemplo, ou sobre a estrutura turística apresentada.

Percebe-se, por meio dos relatos, que o Instagram teve um papel decisivo na escolha do destino da lua de mel, o que vai de acordo com as pesquisas de Varma et al. (2020) ao explicarem que existe uma parcela de usuários que utilizam este meio para o planejamento de viagens. Essa rede social se mostrou uma importante ferramenta para a tomada de decisão, pois através dela se consegue ver as imagens e vídeos do lugar, ler os comentários positivos e negativos de quem já esteve no local, e avaliar se vale a pena ou não ir.

Nos estudos de Barasch et al. (2018), explicou-se que as pessoas gostam de tirar fotos para compartilhar com outras no Instagram. Na presente pesquisa, essa ideia foi ampliada: constatou-se que o uso dessa rede social pode ir além de um simples compartilhamento. As imagens podem influenciar tanto pelo aspecto visual, ao instigar a vontade de conhecer o 
local, quanto pelo aspecto informacional, ao trazer esclarecimentos sobre os locais. Além disso, percebe-se que as postagens podem despertar o interesse do consumidor de realizar uma viagem que muitas vezes nem estava em seus planos, ou mesmo influenciar na mudança de roteiro de viagem.

Nesse sentido, constata-se que a promoção de serviços turísticos não é mais apenas no sentido de empresa para consumidor, mas ocorre, muitas vezes, diretamente de consumidor para consumidor, quando a pessoa desperta o desejo de compra exclusivamente por observações de postagens de experiências de outras pessoas. Alguns autores já trazem essa ideia ao compararem os consumidores como sendo promotores de destinos turísticos que influenciam na decisão de compra (Shuqair \& Cragg, 2017; Yilmaz, 2017; Anagnostopoulou et al., 2019). Portanto, além de confirmar esses estudos, as tipologias encontradas sobre o que mais chama atenção das noivas nas postagens ajudam as empresas relacionadas ao setor turístico a entenderem melhor seus consumidores e direcionarem suas estratégias de mercado.

\subsection{Principais Influenciadores na decisão de compra de destinos turísticos de lua de mel}

Através das falas das entrevistadas, observou-se que a decisão de viajar pode ser influenciada por publicações de diferentes pessoas. A partir disso, foram identificadas quatro categorias de influenciadores denominadas Família, Amigos, Pessoas Desconhecidas e Pessoas Famosas. A Figura 3 descreve e exemplifica cada uma dessas categorias.

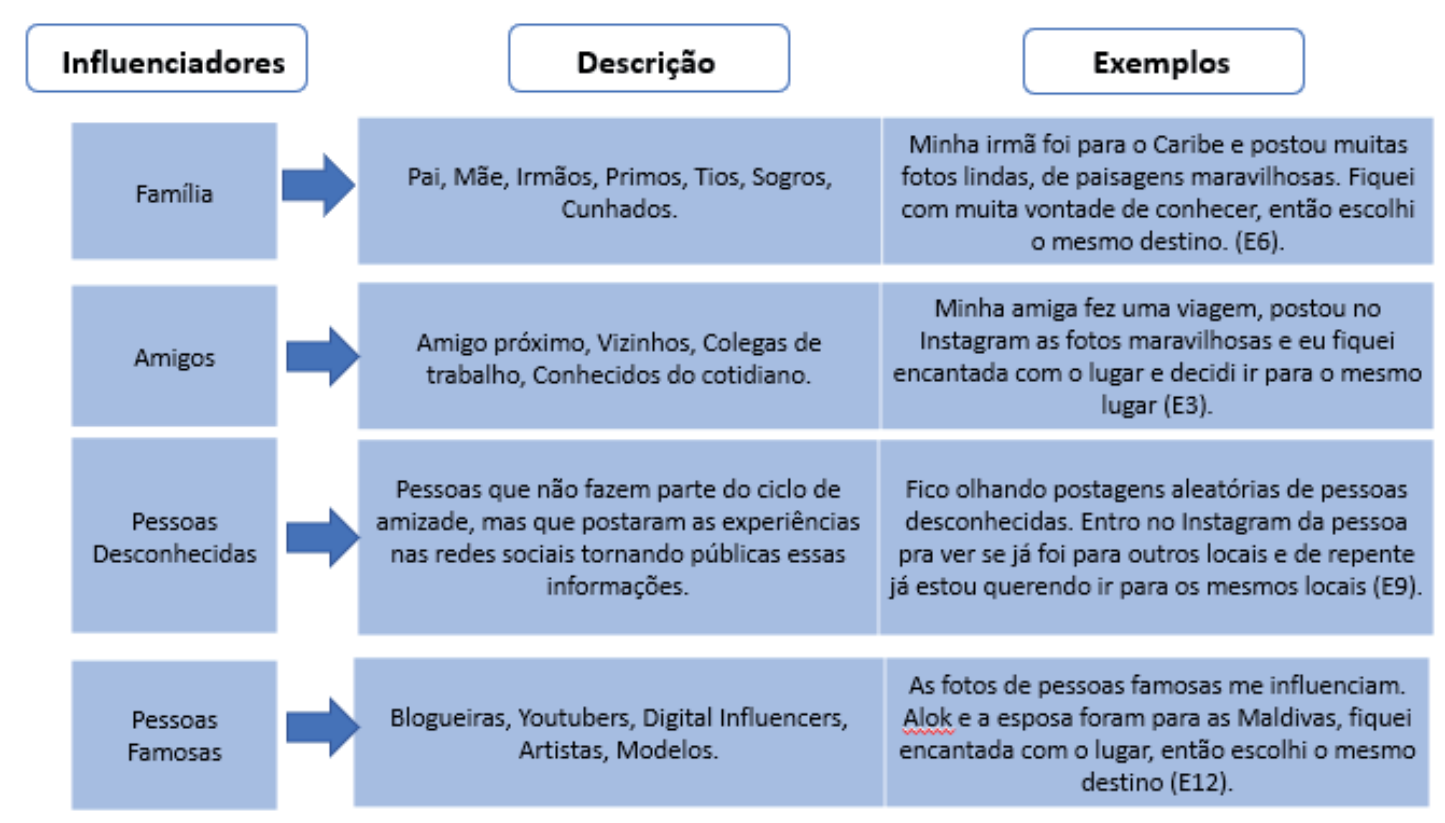

Figura 3 - Principais influenciadores na escolha do destino turístico de lua de mel

Fuente: elaborada pelas autoras (2021).

Ao comparar as quatro categorias, os relatos das entrevistadas evidenciaram que as noivas sofrem uma maior influência de postagens vindas de familiares e, em seguida, dos amigos. Já ao comparar as postagens dessas pessoas próximas com as de pessoas famosas, as 
entrevistadas afirmaram que a pessoa próxima é mais confiável e conta a experiência que realmente vivenciou, indicando porque valeu a pena a viagem. Já as pessoas famosas como artistas ou blogueiras, algumas vezes, estão sendo pagas para fazer a propaganda do lugar. Assim, a informação não é tão confiável quanto a de uma pessoa do mesmo ciclo de amizade que visitou e indicou os melhores lugares de forma autêntica.

Isso também foi visualizado ao comparar as pessoas famosas e as pessoas desconhecidas. Por mais que não sejam próximas e não possam recomendar diretamente, as pessoas fora do ciclo de amizade continuam sendo confiáveis por indicarem realmente aspectos positivos e negativos do que viveram. Nesse sentido, os comentários de desconhecidos são considerados fidedignos, principalmente, quando existem muitas pessoas atestando a veracidade da informação em diferentes postagens.

Nota-se que por mais que o Instagram possibilite aos usuários obter informações vindas de diferentes fontes, os consumidores ainda possuem um certo receio em confiar nos relatos de pessoas desconhecidas. Esse fenômeno, além de reafirmar a explicação de Gao et al. (2018) e Leung et al. (2019) sobre a preferência dos consumidores por relatos e experiências mais pessoais, demonstra que postagens de pessoas desconhecidas podem despertar o interesse de viajar, mas os relatos de pessoas mais próximas, como familiares e amigos, foram considerados como determinantes na escolha do destino turístico.

As categorias encontradas, resultantes da presente pesquisa, vão de acordo com o estudo de Ait-Bakrim et al. (2019), ao explicarem que além da família, amigos, especialistas, artistas e blogueiros, outros consumidores desconhecidos podem influenciar com a publicação de suas informações e experiências.

Além disso, os resultados corroboram com o estudo de Lima e Arruda (2019) e Prentice et al., (2019) que identificaram as redes sociais como um meio capaz de promover o setor turístico numa perspectiva global, rápida e interativa devido à sua capacidade de captar o interesse do consumidor e influenciar a sua decisão. Nesse sentido, pode-se afirmar que no Instagram qualquer tipo de pessoa pode atuar de forma colaborativa ao compartilhar informações sobre produtos ou serviços e, assim, influenciar na tomada de decisão dos consumidores.

\subsection{Processo de decisão de compra de destino turístico de lua de mel}

Conforme salientado nos estudos de Varkaris e Neuhofer (2017) e Hlee et al. (2018), as fotografias funcionam como ferramentas que auxiliam na criação e promoção da imagem de um destino turístico. Assim, as imagens compartilhadas no Instagram reforçam as qualidades e atributos do local e funcionam como fonte de informação.

As noivas têm acesso a essas informações por meio de amigos, familiares e até desconhecidos que já viajaram. Essas informações têm um papel decisivo na escolha do destino turístico de lua de mel, visto que a opinião de uma pessoa que já experienciou o local é considerada de suma importância. Os achados corroboram com os estudos de Guillet et al. (2016) e Lui et al. (2018) ao apontarem que o consumidor busca informações sobre experiências vivenciadas por outras pessoas, pois elas auxiliam na decisão de compra.

Nessa seara, com base nos dados levantados por esta pesquisa e à luz dos modelos clássicos de processo de decisão de compra e do modelo em ambiente virtual sugerido por Lecinski 
(2011), traçou-se um framework do processo de decisão de compra de destinos turísticos de lua de mel, conforme a Figura 4 . O processo se inicia com a visualização da postagem de um destino turístico no Instagram. Posteriormente, percebe-se o desejo para a compra e assim se inicia a etapa de busca por informações, que pode acontecer de forma online ou offline. Em seguida, as informações são selecionadas, é feito o planejamento da viagem e a compra, que pode ser com intermediário e sem intermediário. Por fim, as informações sobre o destino turístico são compartilhadas no Instagram, retroalimentando o processo.

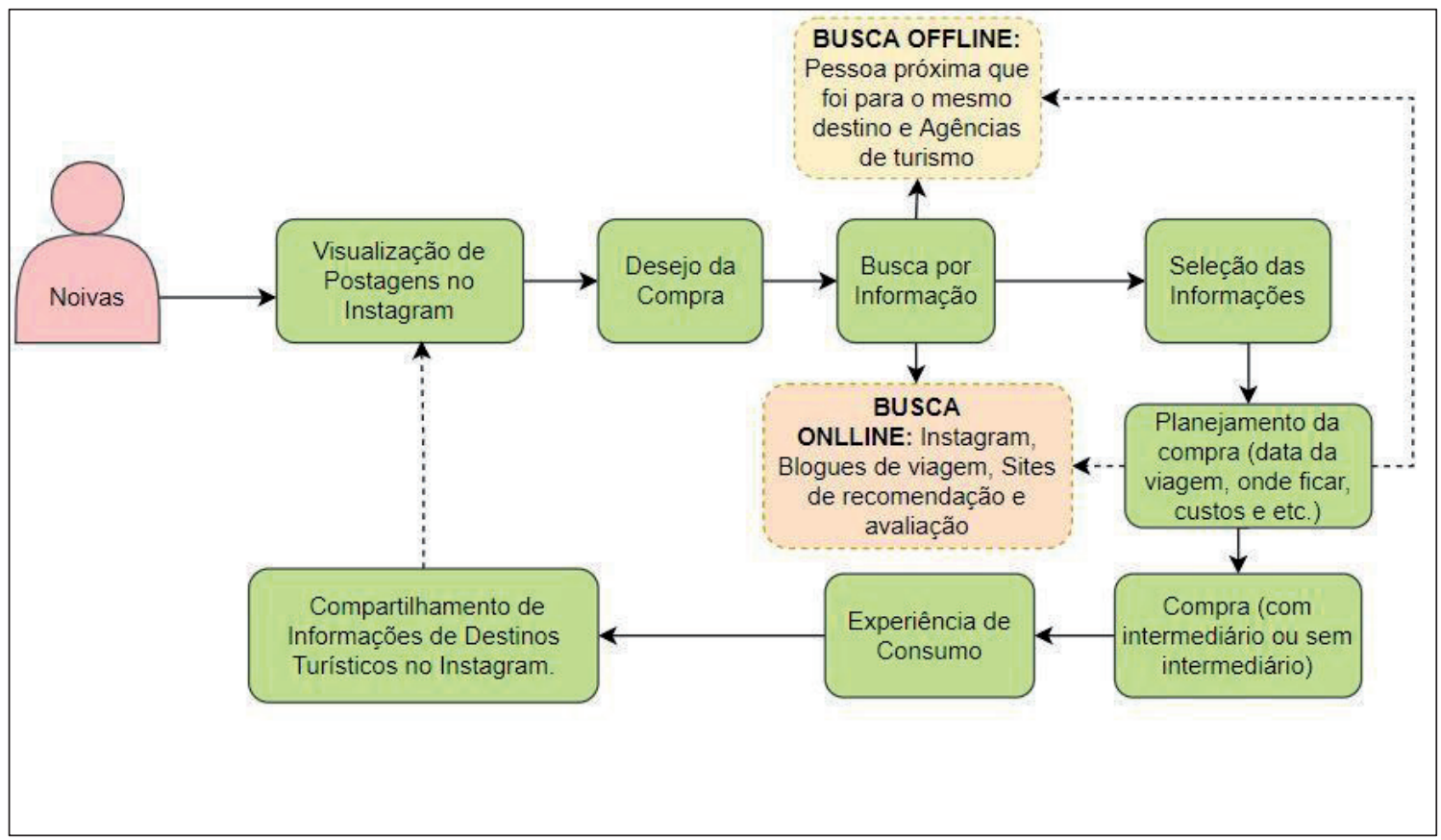

Figura 4 - Processo de decisão de compra de destino turístico de lua de mel

Fuente: elaborada pelas autoras (2021).

Conforme apontado por Lin et al. (2018) e Leung et al. (2019), o ambiente digital proporciona o acesso rápido e fácil a informações de produtos que se deseja consumir, modificando a forma como o consumidor planeja a viagem e escolhe o destino. Assim, ao se deparar com uma postagem de destino turístico no Instagram, a noiva sente o desejo da compra. Esse desejo está relacionado com a vontade de conhecer o lugar, viver as mesmas experiências e postar em suas redes sociais fotos parecidas com as que viu.

A etapa seguinte é a da busca por informações do destino turístico desejado. Esse achado corrobora com o modelo posto por Lecinsk (2011), onde mostra que o consumidor, ao se deparar com um estímulo, busca informações do produto/serviço que quer consumir para decidir a compra. Nessa etapa, as noivas pesquisam tanto no ambiente online como no offline. Na busca online as noivas buscam por hashtags, olham fotos, vídeos e comentários no Instagram, blogues de viagens e sites especializados em recomendações de produtos turísticos. De acordo com Arora et al. (2019) e Prentice et al. (2019), a busca por informações online faz parte do processo decisório de compra.

$\mathrm{Na}$ busca offline as noivas conversam com pessoas próximas a elas que já viajaram para o destino turístico e/ou se informam com agências de turismo. Conforme os estudos de Gao et al. (2018) e Leung et al., (2019), isso ocorre pois o consumidor precisa de informações confiáveis para decidir a compra, por isso busca por relatos e experiências pessoais. 
Sobre a etapa do planejamento, estudos mostram que a forma que se planeja uma viagem mudou com o advento da web 2.0 e das redes sociais (Dantas \& Abreu, 2020; Fernández \& García, 2020). Agora o viajante busca por informações verídicas e espontâneas, por isso valoriza as recomendações feitas por pessoas próximas e por avaliações realizadas por outros viajantes no Instagram. Os dados da pesquisa evidenciaram que, na etapa de planejamento da viagem, as noivas utilizam informações compartilhadas no Instagram e sites especializados em recomendações de produtos turísticos para decidir hotel, passeios, quantos dias ficar no destino e ter uma ideia dos custos.

Após o planejamento da viagem a compra é realizada de duas formas: com ou sem intermediário. No primeiro caso, pode ser realizada offline, por meio de uma agência de viagens, por exemplo. No segundo, o sujeito compra diretamente dos fornecedores, no ambiente virtual. Após a compra, vem a experiência de consumo, que culmina com o compartilhamento de informações do destino turístico. As noivas, ao realizarem suas viagens de lua de mel, postam fotos e vídeos no Instagram. Essas imagens podem servir, futuramente, como fonte de informação para consumidores em potencial. $\mathrm{O}$ achado corrobora com o modelo de Lecinsk (2011) que indica que o consumidor, após a compra, compartilha na internet informações do produto ou serviço consumido, e essas informações vão servir como ZMOT de outros consumidores.

Assim, percebe-se que o processo de decisão de compra se inicia no Instagram, com a visualização da postagem do destino turístico, e finaliza no Instagram, com as noivas postando no Instagram fotos e vídeos da experiência vivida. Esse é o comportamento do turista na atualidade. Antes de viajar realiza pesquisas online, decide o destino, faz comparação de preços e durante a viagem compartilha a experiência em suas redes sociais.

\section{CONSIDERAÇÕES FINAIS}

O presente estudo abordou o fenômeno da grande concentração de publicações de fotos, vídeos e comentários nas redes sociais que passaram a ser grandes influenciadores no processo de decisão de compra de um destino turístico. Assim, buscou-se compreender como as postagens no Instagram influenciam no processo de decisão de compra de destinos turísticos de lua de mel.

Foram encontrados dois tipos de postagens realizadas sobre turismo no Instagram que chamam atenção das noivas. O primeiro tipo, intitulado Postagens Estéticas, possui um apelo visual e três subcategorias: belezas naturais, romantismo e gastronomia. Já o segundo tipo, postagens com enfoque na estrutura turística, traz informações de equipamentos turísticos, e emergiram as subcategorias serviços hoteleiros, atrações turísticas, e bares e restaurantes. As diferenças encontradas nas duas tipologias mostram que as postagens no Instagram desempenham um importante papel no comportamento do consumidor, que deixa de ser apenas um expectador de imagens e vídeos sobre destinos turísticos, e passa a ser um captador de informações para o seu planejamento de viagem.

Em relação aos principais influenciadores do processo de decisão de compra de destinos turísticos de lua de mel, foram identificadas quatro categorias de influenciadores denominados Família, Amigos, Pessoas Desconhecidas e Pessoas Famosas. Os resultados mostraram que o ambiente online permite que cada usuário publique algo em suas redes 
sociais a qualquer momento sobre suas viagens. Entretanto, mesmo que o consumidor saiba que pode obter informações de diferentes fontes, ele acaba confiando mais nas postagens vindas de pessoas próximas como familiares e amigos, pois trazem mais segurança na escolha.

Percebe-se que, de forma espontânea, pessoas comuns acabam atuando com mais eficácia na promoção de destinos turísticos do que pessoas famosas. Apesar disso, deve-se levar em consideração que pessoas desconhecidas e pessoas famosas influenciam as noivas nas decisões de escolha de destinos turísticos de lua de mel. $O$ estudo evidenciou que a partir do momento que a noiva visualiza uma postagem no Instagram, de maneira despretensiosa, ela pode se tornar um objeto de desejo.

Ao caracterizar o processo de decisão de compra de destinos turísticos de lua de mel, observou-se que cada estágio compreende um conjunto de tarefas e passos que os consumidores executam para que possam avançar para o estágio seguinte, como qualquer processo que se desencadeia sequencialmente. Dessa forma, o framework permitiu compreender que o Instagram é uma ferramenta que está presente durante todo o processo de compra de destinos turísticos de lua de mel. As noivas recebem o estímulo ao visualizarem uma postagem nesta rede. A fase de busca por informações também ocorre nesse canal juntamente com o planejamento da viagem, que coleta informações adicionais compartilhadas por outros viajante no Instagram, durante e após a viagem, quando as noivas compartilham fotos, vídeos e informações em seus perfis da rede social.

Ao analisar o framework proposto, é possível observar o caráter retroalimentador do processo de decisão de compra, que se inicia com uma visualização da postagem no Instagram e finaliza com outra postagem nesta rede, retornando para o início do processo. Dessa forma, o Instagram passou a ser uma vitrine de produtos e serviços que substituem as lojas físicas através das novas formas de comunicação. Com campanhas de marketing espontâneas, que são conduzidas pelos consumidores, que acabam atuando como cocriadores das estratégias mercadológicas. Assim, cada usuário vai colaborando com a formação da imagem dos destinos turísticos. À medida que isso ocorre, as estratégias de posicionamento de marca dos destinos e equipamentos turísticos vão saindo do controle dos gestores e passando para os produtores de conteúdo das redes sociais.

Por fim, o estudo proporcionou um melhor entendimento a respeito da influência do Instagram na escolha do destino turístico de lua de mel. Devido à existência de poucos estudos acerca da temática, esta pesquisa se torna relevante tanto para a academia, por produzir trabalhos na área, como para o mercado, ao auxiliar profissionais do setor de turismo a entenderem melhor seu público-alvo e a importância da rede social Instagram como uma ferramenta de trabalho. Dessa maneira, novas implicações podem ser observadas do ponto de vista das empresas, contribuindo para elaborar estratégias que melhorem a imagem de seus estabelecimentos a partir do que é exposto nas redes sociais pelos consumidores.

Quanto às limitações, o estudo focou exclusivamente em destinos turísticos de lua de mel e na perspectiva das noivas. Sugere-se, para trabalhos futuros, realizar estudos que abordem a perspectiva dos noivos, com o intuito de comparar a dinâmica do processo de decisão de compra deste tipo de viagem. Ademais, recomenda-se estudar outros tipos de viagens, como férias em família ou com amigos, e analisar como o Instagram impacta na escolha de destinos 
de diferentes segmentos, podendo, também, aplicar a questão do gênero e idade para verificar se existe uma influência maior ou menor.

\section{Referências}

Ait-Bakrim, A., Attouch, H., Guerreiro, M. \& Perez-Aranda, J. (2019). Examining the relationship between hoteliers' review site use intensity and hotel characteristics. Moroccan hotels. Journal of Spatial and Organizational Dynamics, 7(3), 226-239.

Anagnostopoulou, S., Buhalis, D., Kountouri, I., Manousakis, E., \& Tsekrekos, A. (2019). The impact of online reputation on hotel profitability. International Journal of Contemporary Hospitality Management, 32(1), 20-39. doil: 10.1108/IJCHM-03-2019-0247

Arora, A., Bansal, S., Kandpal, C., Aswani, R., \& Dwivedi, Y. (2019). Measuring social media influencer index- insights from facebook, Twitter and Instagram. Journal of Retailing and Consumer Services, 49(1), 86-101. doi:10.1016/j.jretconser.2019.03.012

Barasch, A., Zauberman, \& G.,Diehl, K. (2018). How the Intention to Share Can Undermine Enjoyment: Photo-Taking Goals and Evaluation of Experiences. Journal of Consumer Research, 44(6), p.12201237. doi: $10.2139 / \mathrm{ssrn} .3113448$

Bardin, I. (2011). Análise de conteúdo. Edições Setenta.

Blackwell, R., Miniard, P. W., \& Engel, J. F. (2008). Comportamento do consumidor. Pioneira Thomson Learning.

Brandt, T., Bendler, J., Neumann, D. (2017). Social media analytics and value creation in urban smart tourism ecosystems. Information \& Management, 54, (6), p. 703-713. doi:org/10.1016/j.im.2017.01.004

Creswell, J. W. (2014). Projeto de pesquisa: métodos qualitativo, quantitativo e misto. 3. ed. Penso.

Dantas, B. L. L., \& Abreu, N.R. R. (2020). An analysis of the influence of the conspicuous consumption of fast fashion on identity construction on instagram. RAM. Revista de Administração Mackenzie, 21(5), p.1-28. doi:10.1590/1678-6971/eRAMG200043

Fernández, N, I., \& García, J. S. (2020). Redes sociales, convergencia y narrativas transmediaen la promoción de las Islas Canarias. Ámbitos. Revista Internacional de Comunicación 48, p. 148-170. doi:10.12795/Ambitos.2020.i48.08

Fontanella, B. J. B., \& Júnior, R. M. (2012). Saturação teórica em pesquisas qualitativas: Contribuições psicanalíticas. Psicologia em Estudo, 17 (1), 63-71, doi:10.1590/S1413-73722012000100008

Gao, B., Li, X., Liu, S., \& Fang, D. (2018). How power distance aects online hotel ratings: The positive moderating roles of hotel chain and reviewers' travel experience. Tourism Management, 65(1), 176186. doi: 10.1016/j.tourman.2017.10.007

Guillet, B. D., Kucukusta, D., \& Liu, L. (2016). An examination of social media marketing in China: how do the top 133 hotel brands perform on the top four Chinese social media sites? Journal of Travel \& Tourism Marketing, 33(6), 783-805. doi:10.1080/10548408.2015.1064337

Handel, B., \& Schwartzstein, J. (2018). Frictions or Mental Gaps: What's Behind the Information We (Don't) Use and When Do We Care? Journal of Economic Perspectives, 32(1), p. 155-178. doi: 10.1257/jep.32.1.155

Hlee, S., Lee, H., \& Koo, C. (2018). Hospitality and Tourism Online Review Research: A Systematic Analysis and Heuristic-Systematic Model. Sustainability, 10(4), p. 11 - 41. doi:10.3390/su10041141 
Jablonska, M. R. (2017). Modern Consumer in Cyberspace: Internet and Psychology Approach. Foundations of Management, 9(1), p. 111-122. doi:10.1515/fman-2017-0009

Jang, H., Lee, S., Lee, S. W., \& Hong, S. K. (2007). Expanding the individual choice-sets model to couples' honeymoon destination selection process. Tourism Management, 28(5), 1299-1314. doi:10.1016/j.tourman.2006.11.008

Lecinski, J. (2011). ZMOT: Conquistando o momento zero da verdade. Google Inc.

Leung, X.Y., Sun, J., \& Bai, B. (2019). Thematic Framework of Social Media Research: State of the Art. Tourism Review, 74(3), 517-53. doi:10.1108/TR-05-2018-0058

Lima, L. C., \& Arruda, D. M.O. (2019). Las evaluaciones online en la decisión de compra de servicios hoteleros. Estudios y Perspectivas en Turismo, 28(1), 942-961.

Lin, H., Bruning, P. F., \& Swarna, H. (2018). Using online opinion leaders to promote the hedonic and utilitarian value of products and services. Business Horizons, 63(5), 458- 482. doi: 10.1016/j.bushor.2018.01.010

Litvin, S. W., Goldsmith, R. E., \& Pan, B. (2018). A retrospective view of electronic word-ofmouth in hospitality and tourism management. International Journal of Contemporary Hospitality Management, 30(1), p. 313-325. doi:10.1108/IJCHM-08-2016-0461

Liu, X., Mehraliyev, F., Liu, C., \& Schuckert, M. (2019). The roles of social media in tourists' choices of travel componentes. Tourist Studies, 20(1), 27- 48. doi:10.1177/1468797619873107

Lui, T. W., Bartosiak, M., Piccoli, G., \& Sadhya, V. (2018). Online review response strategy and its effects on competitive performance. Tourism Management, v. 67, p. 180-190. doi: 10.1016/j.tourman.2018.01.014

Mowen, J. M., \& Minor, M. S. 2006. Comportamento do consumidor. Prentice Hall.

Mukhina, K. D., Rakitin, S. V., \& Visheratin, A. A. (2017). Detection of tourists attraction points using Instagram profiles. Procedia Computer Science, 108, p. 2378-238. doi:10.1016/j.procs.2017.05.131

Pires, A. P. (2008). Amostragem e pesquisa qualitativa: Ensaio teórico e metodológico. In: In: Poupart, J. et al. A pesquisa qualitativa: enfoques epistemológicos e metodológicos. Vozes.

Pourfakhimi, S., Duncan. T., \& Coetzee. W. (2020). Electronic word of mouth in tourism and hospitality consumer behaviour: state of the art. Tourism Review, 75(4), 637-661. doi:10.1108/TR-01-2019-0019

Prentice, C., Han, X.Y., Hua, L.L., \& Hu, L. (2019). The influence of identity-driven customer engagement on purchase intention. Journal of Retailing and Consumer Services. 47, 339-347.

Reyes-Mendez, A., Correia, M.; Matos, N., \& Adap, C. (2020). Understanding Online Consumer Behavior and eWOM Strategies for Sustainable Business Management in the Tourism Industry. Sustainability, 12, p. 72-89. doi:10.3390/su12218972

Schiffman, L. G., \& Kanuk, L. (2009). Comportamento do consumidor. Rio de Janeiro: LTC - Livros Técnicos e Científicos.

Shafiri, S. (2018). Examining the impacts of positive and negative online consumer reviews on behavioral intentions: Role of need for cognitive closure and satisfaction guarantees. Journal of Hospitality Marketing \& Management, p 1-30. doi:10.1080/19368623.2019.1531804 
Sharma, H., \& Aggarwal, A.G. (2019). What factors determine reviewer credibility? An econometric approach validated through predictive modeling, Kybernetes, 49(10), p. 2547-2567. doi:10.1108/K08-2019-0537

Sheth, J. N., Mittal, B., \& Newman, B. I. (2001). Comportamento do Cliente: Indo além do Comportamento do Consumidor. Editora Atlas.

Sholeh, A. \& Rusdi, A., 2019. A New Measurement of Instagram Addiction: Psychometric Properties of The Instagram Addiction Scale (TIAS). Busan, South Korea, s.n., p. 91-97.

Shuqair, S., \& Cragg, P. (2017). The Immediate Impact of Instagram Posts on Changing the Viwers' Perceptions Toward Travel Destinations. Asia Pacific Journal of Advanced Business and Social Studies, 3(2), p.1-12. doi: 10.25275/apjabssv3i2bus1

Silva, M. M., Silva, J. R. H., Marques Junior, S., \& Mendes Filho, L. (2020). Comportamento do consumidor e intenção de compra de serviços hoteleiros: influência ao assistir vídeos na internet. Podium Sport Leisure and Tourism Review, 9(2), 286-307. doi:10.5585/podium.v9i2.15905

Solomon, M. R. (2011). O comportamento do consumidor: comprando, possuindo e sendo. Bookman.

Stake, R. E. (2011). Pesquisa Qualitativa: estudando como as coisas funcionam. Artmed.

Tan, H., LV, X., Liu, X., \& Gursoy., D. (2018). Evaluation nudge: Effect of evaluation mode of online customer reviews on consumers' preferences, Tourism Management, 65(1), p 29-40. doi:10.1016/j.tourman.2017.09.011

Tavakoli, R., \& Mura, P. (2018). Netnography in tourism - Beyond Web 2.0. Annals of Tourism Research, 73, p. 190-192. doi:10.1016/j.annals.2018.06.002

Ünal, C., Dursun, A., \& Caber, M. (2017). A study of domestic honeymoon tourism in Turkey. European Journal of Tourism, Hospitality and Recreation. 8. doi:10.1515/ejthr-2017-0006

Varkaris, E., \& Neuhofer, B. (2017). The Influence of Social Media on the Consumers' Hotel Decision Journey, Journal of Hospitality and Tourism Technology, 8(1), 101-118. doi:10.1108/JHTT-09-20160058

Varma, M., Dhakane, N., \& Pawar, A. (2020). Evaluation of Impact of Instagram on Customer Preferences: The Significance of Online Marketing. International Journal of Scientific \& Technology Research. 9, p.548-554.

Vergara, S. C. (2016). Projetos e relatórios de pesquisa em administração. 16.ed. Atlas.

Xiang, Z., Du, Q., Ma, Y., \& Fan, W. (2017). A comparative analysis of major online review platforms: Implications for social media analytics in hospitality and tourism. Tourism Management, 58(1), 5165. doi: 10.1016/j.tourman.2016.10.001

$\mathrm{Xu}, \mathrm{X}$. (2020). How do consumers in the sharing economy value sharing? Evidence from online reviews. Decision Support Systems, 128, p. 113-162. doi: 10.1016/j.dss.2019.113162

Yilmaz, E. S. (2017). Analyzing the Effects of Comments on Social Networking Sites on Consumer Purchasing Decision Process. International Journal of Academic Research in Business and Social Sciences, 7(6), 140-162. doi:10.6007/IJARBSS/V7-16/2952

\section{Semblanza de los autores}

Lia Chagas de Lima é graduada em Comunicação Social - Publicidade e Propaganda pela Universidade Federal do Ceará (UFC). Tem mestrado acadêmico em Administração concluído 
em 2018 pelo Programa de Pós-Graduação em Administração da Universidade Estadual do Ceará (PPGA - UECE) com ênfase em Marketing. Atualmente, é Doutoranda em Administração pela Universidade Estadual do Ceará e professora universitária. Áreas de pesquisa: Comportamento do consumidor, Processo de decisão de compra, Gestão de marca (Branding), Mídias sociais, Turismo online, Online reviews, Destination branding.

Nathália de Sousa Pereira é Formada em Engenharia de Produção pela Universidade Federal do Ceará. Possui Mestrado em Administração com ênfase em mídias sociais e Gestão Estratégia pela Universidade Estadual do Ceará e especialização em Gestão Logística pelo Centro Universitário Unichristus. Atualmente, é Doutoranda em Administração pela Universidade Estadual do Ceará e professora universitária.

Danielle Miranda de Oliveira Arruda Gomes é Doutora em Administração de Empresas pelo Institut d'Administration d'Entreprises de Y'Université de Nice -França (1992), com Mestrado Acadêmico (DEA) em Administração pelo Institut d’Administration d’Entreprises de Y'Université de Nice -França (1987), Mestrado Profissionalizante (DESS) em Marketing pelo Institut d'Administration d'Entreprises de l'Université de Nice- França (1986) e Graduação em Ciências Contábeis pelo Centro de Ensino Unificado de Brasília -CEUB (1985). É Professora Associada da Universidade Estadual do Ceará -UECE, onde atua na área de Administração com ênfase em Marketing. 